\title{
Blocking heme oxygenase-1 by zinc protoporphyrin reduces tumor hypoxia- mediated VEGF release and inhibits tumor angiogenesis as a potential therapeutic agent against colorectal cancer
}

Chun-Chia Cheng ${ }^{1,2}$, Siao-Syun Guan ${ }^{1}$, Hao-Jhih Yang ${ }^{1}$, Chun-Chao Chang ${ }^{3,4}$, Tsai-Yueh Luo ${ }^{1}$, Jungshan Chang ${ }^{5^{*}}$ and Ai-Sheng $\mathrm{Ho}^{6,7^{*}}$

\begin{abstract}
Background: Hypoxia in tumor niche is one of important factors to start regeneration of blood vessels, leading to increase survival, proliferation, and invasion in cancer cells. Under hypoxia microenvironment, furthermore, steadily increased hypoxia-inducible factor-1a (HIF-1a) is observed, and can increase vascular endothelial growth factor (VEGF) expression and promote angiogenesis. Zinc protoporphyrin (ZnPP), a heme oxygenase-1 (HO-1) inhibitor, is potential to inhibit tumor proliferation and progression. However, the mechanism of ZnPP in inhibition of tumor is not completely clear. We hypothesize that ZnPP may modulate HIF-1 a through inhibiting HO-1, and then inhibit angiogenesis and tumor progression. This study aimed to dissect the mechanism of ZnPP in tumor suppression.

Results: We observed the amount of VEGF was increased in the sera of the colorectal cancer (CRC) patients $(n=34, p<0.05)$. Furthermore, increased VEGF expression was also measured in colorectal cancer cells, HCT-15, culturing under mimicking hypoxic condition. It suggested that hypoxia induced VEGF production from cancer cells. VEGF production was significantly reduced from HCT-15 cells after exposure to HIF-1a inhibitor KC7F2, suggesting that HIF-1 a regulated VEGF production. Moreover, we observed that the HO-1inhibitor ZnPP inhibited the expressions of HIF-1a and VEGF coupled with cell proliferations of HCT-15 cells, suggesting that ZnPP blocked HIF-1a expression, and then inhibited the consequent VEGF production. In the xenograft model, we also observed that the animals exposed to ZnPP displayed much smaller tumor nodules and less degree of angiogenesis with decreased expression of the angiogenesis marker, av $\beta 3$ integrin, compared to that in normal control.

Conclusions: This study demonstrated that VEGF level in serum was elevated in the patients with CRC. The HO-1 inhibitor, ZnPP, possessed the properties of anti-tumor agent by decreasing HIF-1a levels, blocking VEGF production, impairing tumor angiogenesis, and inhibiting tumor growth.
\end{abstract}

Keywords: Angiogenesis, Heme oxygenase-1, Tumor hypoxia, Vascular endothelial growth factor, Zinc protoporphyrin

\footnotetext{
* Correspondence: js.chang@tmu.edu.tw; aisheng49@gmail.com

${ }^{5}$ Graduate Institute of Medical Sciences, School of Medicine, College of Medicine, Taipei Medical University, Taipei, Taiwan

${ }^{6}$ Division of Gastroenterology, Cheng Hsin General Hospital, Taipei, Taiwan

Full list of author information is available at the end of the article
} 


\section{Background}

In the process of tumor progression, the content of oxygen in blood is one of important factors contributes to proliferations, angiogenesis and metastasis in solid tumors. Due to highly accelerated cell divisions and proliferations, tumor cells survive in the microenvironments with deprived oxygen termed as hypoxia, in which may elicit signals to form new blood vessels around tumors for providing additional oxygen and nutrient to tumors [1]. Under this hypoxia condition, deprivation of oxygen in blood causes pathophysiologic consequences within tumor cells, leading to exacerbate tumor progression, tumor invasion and gain the resistance to apoptotic cell death program $[2,3]$. In addition to increased capability in progression, invasion, and proliferation, hypoxia may also strength tumor cells with higher resistance to radiotherapy and chemotherapy [4, 5]. Hypoxia-inducible factor- $1 \alpha$ (HIF-1 $\alpha)$, a regulatory transcription factor, plays a crucial role for tumor cells in responding to lower oxygen in their resident microenvironment. Increased HIF- $1 \alpha$ induced by hypoxia can commit the adaptive changes in gene expressions of tumor cells $[2,6,7]$. It suggests that HIF-1 $\alpha$ is one of potential therapeutic targets in tumors.

Currently, zinc protoporphyrin (ZnPP), a heme oxygenase1 (HO-1) inhibitor, is one of therapeutic candidates of tumors $[8,9]$. It has been documented that the amount of HO- 1 is elevated under hypoxic condition, and this phenomena is mediated by HIF-1 $\alpha$ [10-12]. The physiological function of $\mathrm{HO}-1$ is to cleave heme and give products such as carbon monoxide (CO), iron ion, and biliverdin [12]. $\mathrm{CO}$ and bilirubin derived from biliverdin are antioxidants which may benefit cells in growing and surviving. It implies that $\mathrm{HO}-1$ is a cytoprotective enzyme [13-16]. In addition, other studies also indicate that $\mathrm{HO}-1$ can trigger and regulate HIF-1 $\alpha$ expression in hypoxic tumor cells [17]. The overexpressed HO-1 seems to link with increased tumor growth and drug resistance to chemotherapeutic agents [3, 18].

Since HO-1 is associated with tumor progression, it may be as another therapeutic target in treatment of cancers $[12,19]$ such as colorectal cancer (CRC) [20]. Previous studies have indicated that the drugs by inhibition of $\mathrm{HO}-1$ are considered to be potential therapeutic candidates in the treatment of cancers [21, 22]. ZnPP is well known as an inhibitor of HO-1 and can reduces cancer cell growth. However, this ZnPP-induced inhibitory effect on cancer cell growth is suggested as HO-1 independent manner by Wong et al. [23]. This result suggests that ZnPP may be through other unknown mechanism to inhibit tumor growth other than the known mechanism by inhibition in $\mathrm{HO}-1$ activity. In addition to be an inhibitor of $\mathrm{HO}-1$, $\mathrm{ZnPP}$ also acts as an enzymatic substrate of HO-1. Due to the similarity in structure between $\mathrm{ZnPP}$ and heme, ZnPP can compete with heme to $\mathrm{HO}-1$, leading to reduce the productive levels of $\mathrm{CO}$ and bilirubin [24], which may interfere, disrupt, or detour other cellular signaling pathways to suppress the growth of tumors [23]. However, the detail anti-tumor mechanism of $\mathrm{ZnPP}$ for the CRC therapy is still unclear and need to be evaluated. Therefore, this presented study was to investigate the anti-tumor functions and molecular/cellular mechanisms of $\mathrm{ZnPP}$ in CRC.

It has been demonstrated that tumor hypoxia induces HO-1 expression [10], and also increases the production of vascular endothelial growth factor (VEGF) [6, 25-27]. VEGF is a ligand of VEGF receptor expressed on the endothelial cells, which triggers the signaling for angiogenesis. Since HO-1 may be associated with the expression of HIF- $1 \alpha$ and VEGF [28], we hypothesized that HO-1 inhibitor ZnPP was able to obstruct tumor growth and spread of cancer cells by inhibiting the HO-1-induced HIF- $1 \alpha$ expression coupled with VEGF-mediated angiogenesis. In order to evaluate this hypothesis, we treated human colorectal carcinoma cells (HCT-15) with ZnPP, and then measured the amount of HO-1, HIF- $1 \alpha$ and VEGF expression level. Furthermore, we also evaluated the therapeutic benefits in HCT-15-induced tumor xenografts after treatment of ZnPP such as in the size/volume of tumors and the degree of angiogenesis.

\section{Methods}

Sera and tissues from the patients with colorectal cancer The clinical samples including sera and tissues were collected from Cheng Hsin General Hospital, Taiwan, which was approved by the Institutional Review Board (CHGH-IRB-(240) 100-01). The pairs of tissues including tumors (T) and adjacent non-tumors (NT) from the CRC patients were acquired by surgery. We only collected and analyzed the type of colorectal adenocarcinoma. Total 34 pairs of clinical tissues from the enrolled patients were stained using methylene blue staining and distinguished by a pathologist. Tumor histopathology and severity were determined according to the rules of American Joint Commission on Cancer Staging (AJCCS) system. The 15 healthy volunteers enrolled in this study had no evidence of known CRC. Surgery for identifying normal phenotype was not performed in the healthy volunteers due to ethical issues.

\section{HCT-15 culture and tumor xenograft model}

Human colorectal carcinoma cells (HCT-15) were cultured in F12K medium with $10 \%$ of fetal bovine serum. All cells were incubated at $37{ }^{\circ} \mathrm{C}$ and $5 \% \mathrm{CO}_{2}$. Male nude mice were purchased from BioLASCO Taiwan Co., Ltd, Taiwan. The 5-week-old mice were housed in a $12 \mathrm{~h}$ light cycle at $22{ }^{\circ} \mathrm{C}$. The animal studies were approved by the institutive ethical review committee in Institute of Nuclear Energy Research, which followed the NIH guidelines on the care and welfare of laboratory animals. HCT-15 cells $\left(2 \times 10^{6}\right)$ 
were subcutaneously (s.c.) inoculated into the right leg of nude mice. Tumors were established for 10 days before the tumor treatment and imaging.

\section{Tumor hypoxia}

For control group, HCT-15 cells were cultured in the normal condition at $37{ }^{\circ} \mathrm{C}$ and $5 \% \mathrm{CO}_{2}$. To mimic a hypoxic condition, HCT- 15 was incubated at $37{ }^{\circ} \mathrm{C}$ with $21 \% \mathrm{CO}_{2}$ in an anaerobic incubator (Mitsubishi Gas Chemical, Tokyo, Japan). HCT-15 cells were harvested for detecting the carbonic anhydrase 9 (CA9), HO-1, and $\beta$-actin expressions using Western blots when HCT15 cells were incubated in $24 \mathrm{~h}$ and $48 \mathrm{~h}$.

\section{Tumor inhibition in vitro}

HCT-15 cells with $50 \%$ confluence were cultured in F12K medium with $2.5 \mu \mathrm{M}$ or $10 \mu \mathrm{M}$ of hemin and $\mathrm{ZnPP}$ for $24 \mathrm{~h}$. The tumor cells without treatment were used as the experimental controls. The cell numbers were calculated using an automatic cell counter (Invitrogen, Massachusetts, USA). Moreover, the cells treated with or without $10 \mu \mathrm{M}$ of hemin and $\mathrm{ZnPP}$ were collected and analyzed $(n=3)$ using Western blots for detecting HIF- $1 \alpha$, HO-1, glucose regulated protein 78 (GRP78), and $\beta$-actin. Apoptosis was evaluated by Annexin V-FITC staining. The cells were washed and harvested for flow cytometric analysis in a FACSCalibur Flow Cytometer (BD Biosciences, New Jersey, USA).

\section{VEGF measurement}

VEGF levels were measured using a VEGF enzymelinked immunosorbent assay (ELISA) kit (Invitrogen, Massachusetts, USA). There were three conditions where the mediums were collected and measured. The mediums were collected where (1) HCT-15 cells with $90 \%$ confluence were cultured in normoxia or hypoxia condition, (2) HCT-15 cells with $90 \%$ confluence were treated with $2.5 \mu \mathrm{M}$ or $10 \mu \mathrm{M}$ of hemin and $\mathrm{ZnPP}$, and cultured in normoxia condition for $24 \mathrm{~h}$, and (3) HCT-15 cells with $90 \%$ confluence were treated with $2.5 \mu \mathrm{M}$ or $10 \mu \mathrm{M}$ of hemin and $\mathrm{ZnPP}$, and cultured in hypoxia condition for $24 \mathrm{~h}$. VEGF measurements were performed according to the manufacturer's instructions and quality control was ensured.

\section{Western blots}

Cells were lysed in the buffer containing $150 \mathrm{mM} \mathrm{NaCl}$, $1 \%$ NP-40, $0.1 \%$ SDS, and $50 \mathrm{mM}$ Tris- $\mathrm{HCl}$ (pH8.0). The protein samples were mixed with two-fold sample buffer $(75 \mathrm{mM}$ of Tris-HCl, pH 6.8, $10 \%$ (v/v) glycerol, $2 \%$ SDS (w/v), $0.002 \%(w / v)$ bromophenol blue). Total $20 \mu \mathrm{g}$ of each sample was analyzed in $10 \%$ sodium dodecyl sulfate polyacrylamide gel electrophoresis, and then transferred onto the Immobilon P membranes (Merck Millipore,
Massachusetts, USA). These PVDF membranes were blocked in $3 \%$ skim milk for $1 \mathrm{~h}$ at room temperature. PVDF membranes were then incubated with primary antibodies $(1 \mu \mathrm{g} / \mathrm{ml})$ overnight at $4{ }^{\circ} \mathrm{C}$, and washed using Tris buffered saline with $0.1 \%$ tween-20. After washing, PVDF membranes were incubated with horseradish peroxidase-conjugated secondary antibody $(1 \mu \mathrm{g} / \mathrm{ml})$ for $2 \mathrm{~h}$ at room temperature. The immunoreactive proteins were detected using ECL (enhanced chemiluminescence, Bio-Rad, California, USA) coupling with a LAS-4000 mini device (Fujifilm, Tokyo, Japan).

\section{Angiogenesis imaging in vivo}

The PBS $(n=3)$ or $100 \mu \mathrm{g}$ of $\operatorname{ZnPP}(n=3)$ were injected into HCT-15 tumor xenografts from tail vein. After $24 \mathrm{~h}$ circulation, the angiogenesis detecting agent labeled with the near-infrared fluorescence (AngioSense 680 EX, PerkinElmer, Massachusetts, USA) was intravenously injected into tail vein of HCT-15 xenograft model. Then, the in vivo imaging system (IVIS, PerkinElmer, Massachusetts, USA) was performed to capture the fluorescent images for detecting angiogenesis distribution.

\section{Inhibition of tumor growth by ZnPP in vivo}

For testing the anti-tumor effects of $\mathrm{ZnPP}$, the mice were randomly divided to three groups: PBS as control $(n=3)$, $10 \mu \mathrm{g}$ of $\mathrm{ZnPP}(n=3)$, and $100 \mu \mathrm{g}$ of $\mathrm{ZnPP}(n=3)$. The mice were treated in day 11,13 , and 16 after tumor implantation. The tumor sizes were measured using a digital caliper and recorded in day $11,13,16,18$, and 20 . Tumor volumes were recorded and calculated using the formula: $0.52 \times$ width $^{2} \mathrm{x}$ length, herein the width represents the smaller tumor diameter. The mice were sacrificed in day 20 , and tumors were analyzed using Western blots for detecting $\alpha v \beta 3$ integrin and $\beta$-actin.

\section{Statistical analysis}

The bands in Western blots were quantified by densitometric analysis using Multi Gauge v3.2 software (Fujifilm, Tokyo, Japan). Statistical analysis was performed using GraphPad Prism V5.01 software (GraphPad Software, Inc., California, USA). All analysis data with more than two groups were performed by ANOVA followed by post-hoc analysis using Bonferroni's test. Student's $t$ test was used to compare two groups. The analysis of receiver operating characteristic curve was performed to clarify the cut-off value using SPSS software. Data were presented as mean \pm SD. The significance difference ( $p$ value) was acceptable as $p<0.05$.

\section{Results}

\section{VEGF elevated in the sera of CRC patients}

To compare VEGF levels in sera between the CRC patients and the normal individuals, sera samples were 
acquired and measured using the ELISA assay. Thirtyfour CRC patients and 15 healthy volunteers were enrolled and participated in this study. The tumor tissues were first collected by surgical operation and then stained using methylene blue dye for distinguishing tumors from the adjacent non-tumor tissues in each clinical biopsy specimens (Fig. 1a). Due to the medical ethics, the normal tissues from the healthy volunteers were not collected. The serological VEGF levels in CRC group were $222 \pm 38 \mathrm{pg} / \mathrm{ml}$ compared to that in healthy group measured as $105 \pm$ $31 \mathrm{pg} / \mathrm{ml}$ (Fig. 1b), indicating the significantly increased VEGF expression in sera of CRC patients. Moreover, the sensitivity and specificity of VEGF were 0.618 and 0.667 , respectively, with a cut-off value of $122.5 \mathrm{pg} / \mathrm{ml}$ according to the analysis of receiver operating characteristic curve.

\section{Tumor hypoxia promoted cell growth and enhanced HO-1 and VEGF expression in HCT-15 cells}

To elevate the role of hypoxia on cell survival, HCT-15 cells were cultured on hypoxic incubator supplemented with $21 \% \mathrm{CO}_{2}$ as described in the section of Methods and Materials. HCT-15 cells growing under hypoxic condition displayed significantly higher amount of carbonic anhydrase-9 (CA9), a hypoxic marker, compared to cells growing under normoxia condition (Fig. 2a). Furthermore, HCT-15 cells culturing in hypoxic condition gained more than $50 \%$ in cell viability compared to normoxia (Fig. 2b). Since HIF-1 $\alpha$ was more stable with longer half-life in activity under hypoxia, leading to promote tumor angiogenesis $[6,29]$, we further measured the expressions of HO-1 and VEGF in HCT-15 cells culturing in hypoxic condition. To measure the changes of HO-1 levels expressed from HCT-15 growing under normoxia and hypoxia, cell protein lysates were acquired and then detected using Western blots. The detection of VEGF secreted from HCT-15 into cultured medium was measured using ELISA. We found that HO-1 expression was significantly increased in HCT15 cells cultured either for $24 \mathrm{~h}$ or $48 \mathrm{~h}$ in hypoxic condition (Fig. 2c). Moreover, the amounts of VEGF in cell supernatant derived from cells culturing under hypoxia and normoxia were measured and the results revealed more than 3-fold increase in VEGF production from cells grew under hypoxic condition (Fig. 2d). Moreover, the hypoxia-induced VEGF production from HCT-15 cells was blocked by KC7F2, a HIF-1 $\alpha$ inhibitor. These results suggested that HIF-1 $\alpha$ played an important role on regulation to induced HO-1 and VEGF expressions.

\section{ZnPP inhibited tumor proliferation coupling with reduced HIF-1a and HO-1 expressions \\ Since hypoxia-induced HO-1 was observed in tumor cells, we hypothesized that HO-1 may act as a therapeutic target for treatment of cancers. ZnPP is a competitive HO- 1 in- hibitor for competing with heme. Therefore, we investi- gated the inhibitory roles of $\mathrm{ZnPP}$ on survival of HCT-15}

A
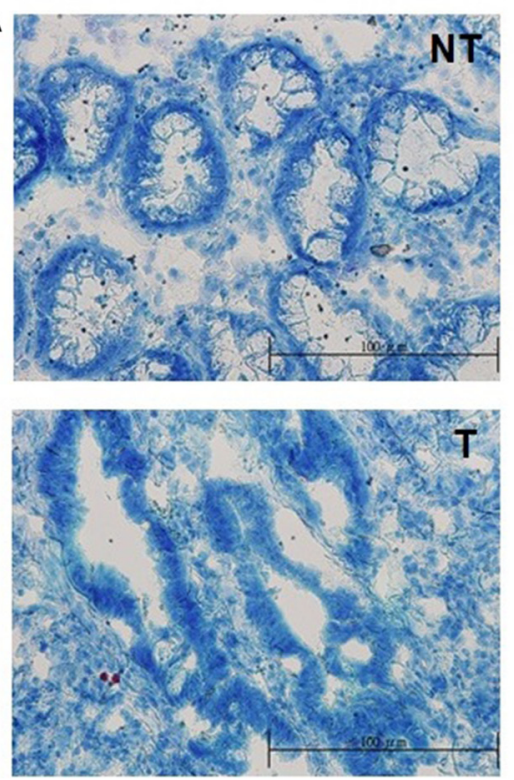

B

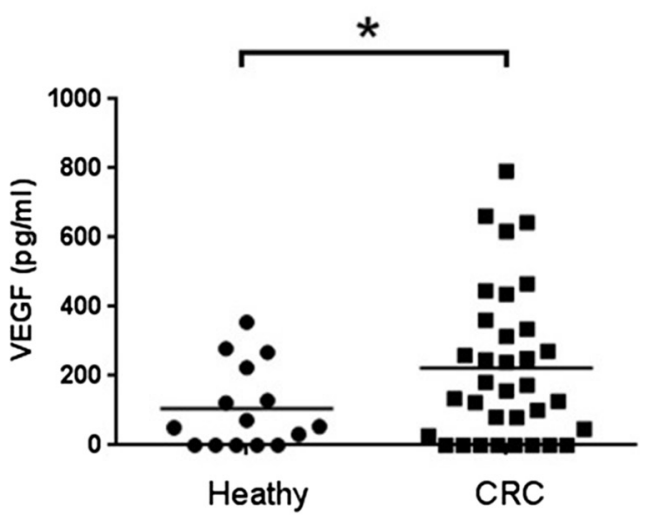

Fig. 1 VEGF overexpressed in the sera of the enrolled patients with colorectal cancer. a Total 34 pairs of clinical tissues from the enrolled patients were stained using methylene blue staining and distinguished by a pathologist. The healthy volunteers were not tested due to ethical issues, who had no evidence of known CRC. NT: non-tumor; T: tumor. Scale bar: $100 \mu \mathrm{m}$. b VEGF levels were increased in the sera of patients with colorectal cancer $(n=34)$ compared to that in healthy volunteers $(n=15) .{ }^{*} p<0.05$ 


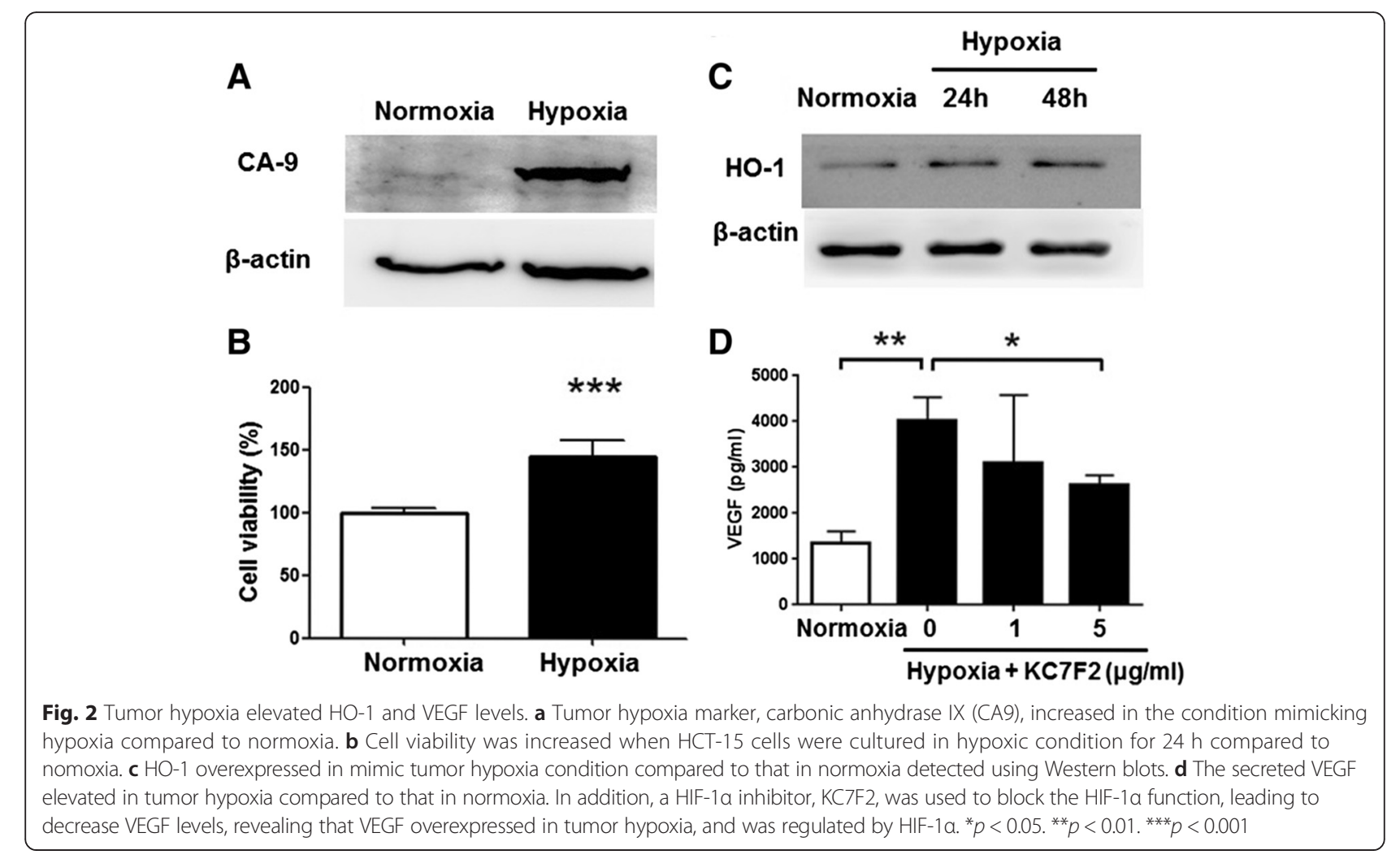

cells. HTC-15 cells were cultured with medium containing 2.5 or $10 \mu \mathrm{M}$ and the result demonstrated that numbers of HCT-15 cells were significantly decreased with $\sim 75 \%$ reduction at $10 \mu \mathrm{M}$ of $\mathrm{ZnPP}(p<0.05)$ but no cytotoxic effect at $2.5 \mu \mathrm{M}$. Moreover, hemin, a HO-1 inducer, did not statistically alter the numbers of cells either at 2.5 or $10 \mu \mathrm{M}$ of hemin (Fig. 3a). In order to detail the cytotoxic mechanism of ZnPP on HCT-15 cells, we analyzed and measured several candidate proteins in expressions level such as HO-1, HIF- $1 \alpha$, and endoplasmic reticulum (ER) stress GRP78 in HCT-15 cells cultured in medium either containing $10 \mu \mathrm{M}$ of hemin or $10 \mu \mathrm{M}$ of $\mathrm{ZnPP}$. The results indicated that hemin significantly increased amounts of HIF- $1 \alpha$ and HO- 1 , although no statistically significance in hemin-enhanced HO-1 production. In contrast to hemin, ZnPP significantly reduced HIF- $1 \alpha$ and HO-1 expressions (Fig. 3b \& c). Both hemin and ZnPP did not affect the expression of GRP78, an ER stress protein overexpressed under extreme conditions countering to non-specific stimulations [30]. To characterize the potential mechanism of ZnPP-induced reduction in cell numbers, the apoptotic analysis was performed and the results demonstrated that $\mathrm{ZnPP}$ at $10 \mu \mathrm{M}$ did not trigger apoptotic program in HCT-15 cells (Fig. 3d). We presumed that ZnPP may reduce HIF- $1 \alpha$ expression through inhibiting $\mathrm{HO}-1$ activity, and consequently inhibit tumor proliferation.

\section{ZnPP reduced hypoxia-mediated VEGF release in HCT-15 cells in vitro}

Our data demonstrated that hypoxia mediated HO-1 production and VEGF release from HCT-15 cells, ZnPP, however, inhibited HIF-1 $\alpha$ expression. Therefore, we were interested in evaluating the effects of ZnPP on VEGF expression in HCT-15 cells. To collect and measure the amounts of VEGF in supernatant of cultured medium, the HCT-15 cells were cultured in medium containing either with hemin or $\mathrm{ZnPP}$ at concentration of 2.5 or $10 \mu \mathrm{M}$ for $24 \mathrm{~h}$ incubation. VEGF levels were then measured using ELISA assay. The results showed that $\mathrm{ZnPP}$ at $10 \mu \mathrm{M}$ significantly reduced VEGF levels by $40 \%(262 \pm 18 \mathrm{pg} / \mathrm{ml})$ compared to control group without any treatments (438 \pm $62 \mathrm{pg} / \mathrm{ml}$ ). Meanwhile, hemin displayed no any modulating effects on VEGF production in HCT-15 cells either at 2.5 or $10 \mu \mathrm{M}$ (Fig. 4a). This result indicated that $\mathrm{ZnPP}$ specifically reduced VEGF release from HCT-15 cells. Since tumor hypoxia specifically induced VEGF expression and release as shown in Fig. 2d, we would like to see whether ZnPP can interfere hypoxia-induced VEGF production or not. We cultured cells under hypoxic chamber either with or without treatments of $\mathrm{ZnPP}$ and then the measurements of VEGF were acquired and compared. The results first confirmed that hypoxia induced VEGF production from HCT-15 cells. Furthermore, ZnPP 

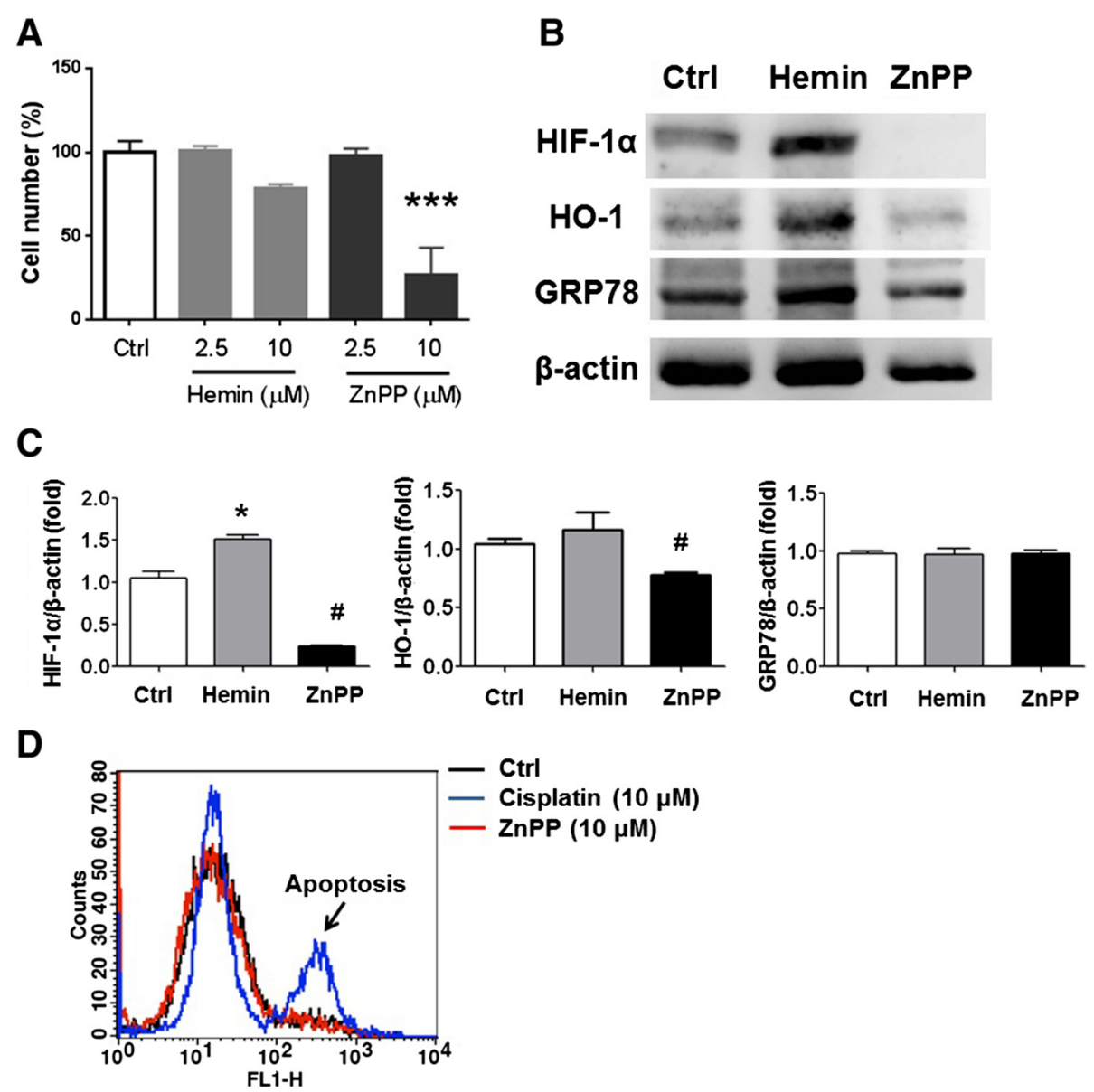

Fig. 3 ZnPP inhibited cell proliferation and decreased HIF-1a levels in HCT-15 cells. a HCT-15 cells cultured in normoxia were treated with hemin, a HO-1 inducer, or ZnPP, a HO-1 inhibitor, using a dose-dependent manner, and the cell number was counted and compared. The cells without treatment were used as control (Ctrl). ZnPP $(10 \mu \mathrm{M})$ significantly inhibited the HCT-15 cell viability, but hemin did not. b \& c The treated cells were harvested and investigated $(n=3)$ for detecting the expressions of HO-1, HIF-1a, ER stress marker GRP78, and $\beta$-actin. Hemin increased HIF-1a and HO-1 (without significance), but ZnPP decreased HIF-1a and HO-1. The ratio of GRP78/ $\beta$-actin was equivalent among the groups as an indicator excluding the treated effects derived from hemin or ZnPP. $\mathbf{d}$ Furthermore, apoptosis was not detected in HCT-15 cells treated with $10 \mu \mathrm{M}$ of ZnPP, whereas $10 \mu \mathrm{M}$ of cisplatin was used as a positive control to induce apoptosis, indicating that ZnPP inhibited HCT-15 cell proliferation without leading to apoptosis. ${ }^{*} p<0.05 .{ }^{* * *} p<0.001 .{ }^{\#} p<0.05$ compared to ctrl

inhibited hypoxia-induced VEGF production in a dosedependently manner (Fig 4b).

\section{ZnPP reduced tumor angiogenesis and tumor growth in HCT-15-induced xenografts}

We demonstrated that ZnPP-mediating reduction in HCT-15 proliferation combined with decreased VEGF release, so we further liked to investigate the in vivo inhibitory potential of ZnPP on tumor and angiogenesis in animals suffered with cancers. VEGF are positively associated with angiogenesis during progression of cancers. To characterize the inhibitory potential of $\mathrm{ZnPP}$ in angiogenesis, ZnPP was intravenously administrated into xenografts with HCT-15 cancer cells and then angiogenesis were detected and analyzed using an in vivo imaging system (IVIS) coupled with a near-infrared labeled fluorescent macromolecule (AngioSense 680 EX, Perkin Elmer, Massachusetts, USA) via intravenous administration. The results indicated that less fluorescencelabeled area combined with lower fluorescent intensity ( $\sim 50 \%$ reduction) in the animals pretreated with $\mathrm{ZnPP}$ compared to that in animals only treated with PBS (Fig. 5a and b), revealing that $\mathrm{ZnPP}$ reduced tumor angiogenesis in vivo. In order to confirm the results derived from imaging analysis by IVIS, we measured the amount of $\alpha v \beta 3$ integrin using Western blotting. According to the literatures, $\alpha v \beta 3$ is one of angiogenetic markers [31, 32]. The $\alpha \mathrm{v} \beta 3$ integrin expressed from $\mathrm{ZnPP}$-treated tumor tissues were significantly reduced by $50 \%$ compared to that in PBS treatment (Fig. $5 \mathrm{c}$ and d). The decreased ratio of $\alpha v \beta 3$ integrin was consistent with that our previous observation in IVIS detection of 

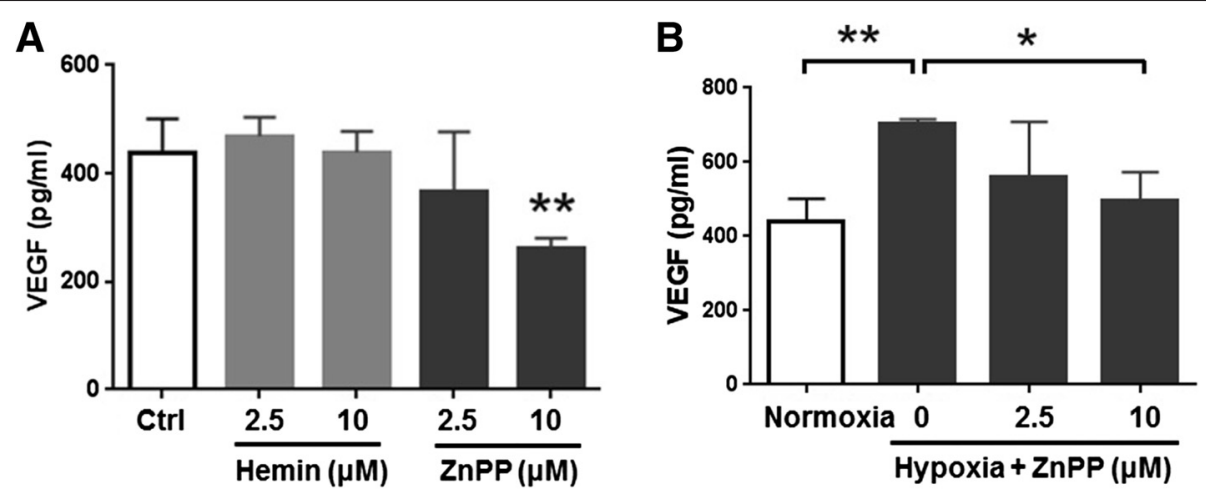

Fig. $4 \mathrm{ZnPP}$ reduced tumor hypoxia-mediated VEGF release. a HCT-15 cells were treated with hemin or ZnPP cultured in normoxia, and the cultured mediums were collected and investigated using ELISA assay. We found that ZnPP $(10 \mu \mathrm{M})$ decreased VEGF secretion in HCT-15 cells, but hemin did not. $\mathbf{b}$ HCT-15 cells was treated with ZnPP and cultured in hypoxia condition. Tumor hypoxia increased VEGF, but ZnPP reduced hypoxia-induced VEGF levels. ${ }^{*} p<0.05 .{ }^{* *} p<0.01$

tumor angiogenesis. These results indicated that $\mathrm{ZnPP}$ inhibited tumor angiogenesis and this ZnPP-mediated anti-angiogenesis effect was VEGF dependent.

Beside the role of $\mathrm{ZnPP}$ on anti-angiogenesis, we also would like to evaluate the therapeutic effects of $\mathrm{ZnPP}$ on HCT-15-induced xenografts. Since ZnPP was demonstrated to reduce VEGF-triggered angiogenesis, $\mathrm{ZnPP}$ was injected into HCT-15-induced xenografts through tail vein at the day 11,13 , and 16 after tumor implantation. We found that both concentration at $10 \mu \mathrm{g}$ and $100 \mu \mathrm{g}$ of ZnPP significantly reduced the tumor size compared to PBS group (Fig. 6a and b). The results indicated that ZnPP may be a potential therapeutic candidate for patients with colorectal cancer.

\section{Discussion}

$\mathrm{ZnPP}$, one of metalloporphyrins, is a HO-1 inhibitor by competing metabolized heme. A previous study suggests that tin protoporphyrin IX ( $\mathrm{SnPP})$ is the most potent HO-1 inhibitor in the internal anal sphincter (IAS) smooth muscle [33]. Literatures also have indicated that other inhibitors but not SnPP show strong inhibitory function on HO-1 activity in liver [33]. It suggested the HO-1 inhibitors are belonging to tissue-specific inhibitors.

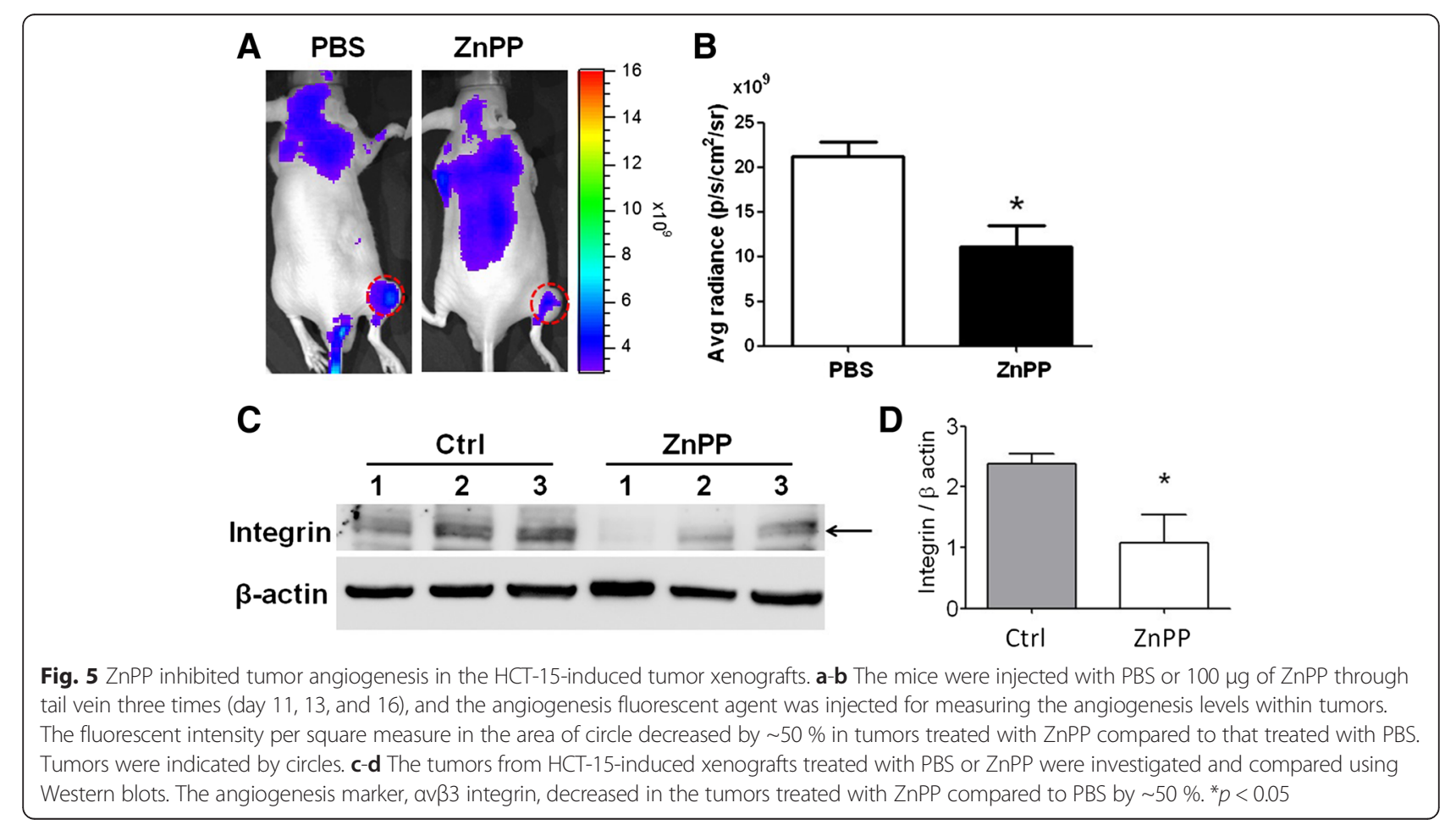




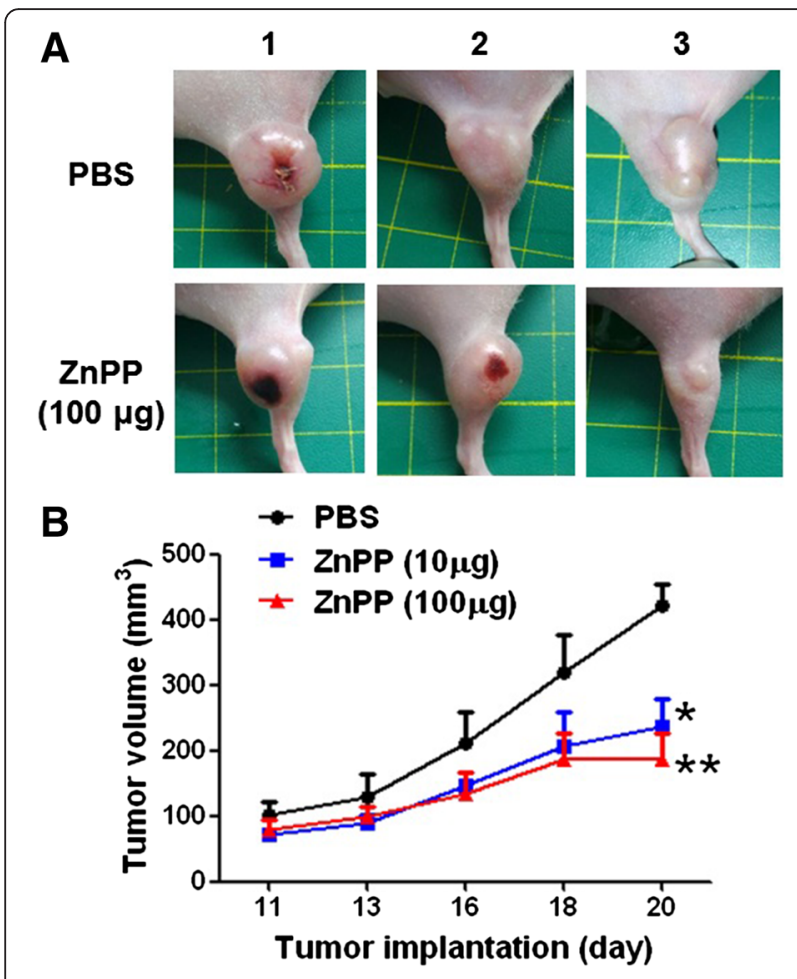

Fig. 6 ZnPP inhibited tumor growth in the HCt-15-induced tumor xenografts as a potential therapeutic agent. a The mice were treated with PBS, $10 \mu \mathrm{g}$ or $100 \mu \mathrm{g}$ of ZnPP three times (day 11, 13, and 16), and the tumor sizes were recorded and compared. We found that $100 \mu \mathrm{g}$ of ZnPP significantly reduced the tumor growth, and $\mathbf{b}$ decreased tumor volume by $\sim 50 \%$. ${ }^{*} p<0.05 .{ }^{* *} p<0.01$

Compared to other metalloporphyrins such as copper protoporphyrin (CuPP), ZnPP displays more potent inhibitory function on HO-1 activity in tumor [34], indicating that ZnPP may be a good candidate to inhibit growth and progression of tumors. A particular study indicates that ZnPP suppresses cyclin D1 gene expression in cancer cells is HO-1 independent, but SnPP does not [35]. Another study demonstrated that ZnPP-induced tumor suppression effect is a HO-1-independent manner, but via in inhibiting the $\mathrm{Wnt} / \beta$-catenin signaling pathway in cancer cells [36]. Thus, it is likely that ZnPP, a HO-1 inhibitor, not only reduces the HO-1 activity, but also triggers other inhibitory effects on other mechanism associated with tumor cell progression.

In our current study, we found that ZnPP prohibited cell proliferation in HCT-15 cells, decreased HIF- $1 \alpha$ and HO-1 levels, reduced VEGF release, and inhibited angiogenesis. Tumor hypoxia prolongs HIF-1 $\alpha$ activity, and induces VEGF expression, leading to promote angiogenesis and malignant tumor growth. In this study, we demonstrated that KC7F2, a HIF-1 $\alpha$ inhibitor, inhibited HIF-1 $\alpha$ mediated VEGF production. Furthermore, HO-1 directly regulated HIF- $1 \alpha$ production [17]. Therefore, HO-1 inhibitor such as $\mathrm{ZnPP}$ was demonstrated with capability in reduction of HIF-1 $\alpha$ expression and VEGF levels in this study. We speculated that tumor inhibitory effect of $\mathrm{ZnPP}$ was partially due to decreasing HIF- $1 \alpha$ expression through reducing HO-1 activity, and then consequently decreased tumor angiogenesis.

Tumor hypoxia often derived from tumor-lodging microenvironment in many solid tumors which receive limited amounts of oxygen supply promptly promotes the formation of new blood vessels. The advanced tumors exhibit large volume coupled with higher degree in angiogenesis [37]. In order to determine the inhibitory effects of $\mathrm{ZnPP}$ to angiogenesis, we selected adequate tumor size near to $100 \mathrm{~mm}^{3}$ for imaging angiogenesis after administration of $\mathrm{ZnPP}$, in which was sufficient area for observing fluorescent signals on the location of implanted tumors. Besides, since the in vivo near-infrared AngioSense 680 EX fluorescent agent is a PEGylated large scaffold $(250 \mathrm{kDa})$ belonging to a non-targeted tumor vascular fluorescent agents [38, 39], we utilized this agent to detect tumor angiogenesis. The results demonstrated that $\mathrm{ZnPP}$ significantly reduced the degree of tumor angiogenesis in the HCT-15-induced tumor xenografts.

It has been well known that hypoxia-induced HIF- $1 \alpha$ mediates the down-stream signaling pathways for various forms of genes for response to tumor progression and invasion. Since elevated HIF- $1 \alpha$ participates in tumor progression, HIF- $1 \alpha$ is considered as one of tumor markers and can be useful as a targeted candidate for anti-tumor therapeutics. The therapeutic approaches by targeting to HIF-1 $\alpha$ may impact several fields, including (a) reduction of HIF- $1 \alpha$ synthesis, (b) accelerating degradation of HIF$1 \alpha$, and (c) inhibiting the transactivation of the HIF- $1 \alpha-$ mediated down-stream signaling events. In contrast to HO-1 inducer hemin increased HIF- $1 \alpha$ levels, this study demonstrated that HO-1 inhibitor ZnPP reduced HIF-1 $\alpha$ expression, indicating that $\mathrm{HO}-1$ may regulate amounts of HIF- $1 \alpha$, and can be qualified as a targeted protein for developing anti-tumor therapeutics.

A previous study has reported that both $\mathrm{ZnPP}$ and hemin are an oxidative iron-binding porphyrin, inhibits $\mathrm{CoCl}_{2}$-induced HIF- $1 \alpha$ expression through accelerating HIF-1 $\alpha$ degradation [40]. However, this study revealed the induction of HIF-1 $\alpha$ by hemin in the normal cultured condition, but only ZnPP reduced HIF-1 $\alpha$ levels. The difference between hemin (iron) and ZnPP (zinc) is (a) in the function either to induce or inhibit HO-1 activity, and (b) the various forms of metals enclosed in the porphyrins. In addition to regulation of HO-1 activity, zinc metal may have other effects or biological roles to modulate the activity of HIF- $1 \alpha$ in tumors [41, 42]. Our results revealed that $\mathrm{ZnPP}$ possessed higher inhibitory effects than hemin on HIF-1 $\alpha$ expression and proliferation of tumor cells, suggesting that $\mathrm{ZnPP}$ is a therapeutic candidate for treatment of cancers. 


\section{Conclusions}

In conclusion, this study demonstrated that $\mathrm{ZnPP}$ is not only a HO-1 inhibitor, but also a potential anti-tumor agent inhibiting tumor proliferation. We found that $\mathrm{ZnPP}$ reduced HIF-1 $\alpha$ expression in HCT-15 cells, and consequently inhibited hypoxia-mediated VEGF release. Moreover, we also demonstrated that ZnPP inhibited HCT-15 cell proliferation, and reduced tumor growth in the HCT-15-induced tumor xenografts as an ideal therapeutic agent. The angiogenesis level was decreased in the tumor exposed to $\mathrm{ZnPP}$ compared to the group treated without exposure of ZnPP. These findings may detail the ZnPP-mediated anti-tumor mechanism. Since the results revealed that VEGF was highly elevated in the sera of CRC patients using an ELISA assay, we speculated and suggested that ZnPP may be a potential therapeutic agent against CRC.

\section{Competing interests}

All authors declare that they have no competing interests.

\section{Authors' contributions}

CC Cheng carried out VEGF measurement, IVIS tumor imaging, tumor inhibitory assay, and manuscript writing. SS Guan carried out Western blots. HJ Yang participated in the cell culture and VEGF measurement. CC Chang participated in the study design. TY Luo participated in the study design. J Chang participated in the experimental design and helped revise the manuscript. AS HO participated in the study design, and collected the clinical samples. The authors all read and approved the final manuscript.

\section{Acknowledgements}

This study was supported by the grant ARA010201 from Atomic Energy Council of Republic of China, and the grant 104-03 of Cheng Hsin General Hospital.

\begin{abstract}
Author details
${ }^{1}$ Institute of Nuclear Energy Research, Atomic Energy Council, Taoyuan, Taiwan. ${ }^{2}$ Institute of Clinical Medicine, National Yang-Ming University, Taipei, Taiwan. ${ }^{3}$ Division of Gastroenterology and Hepatology, Department of Internal Medicine, Taipei Medical University Hospital, Taipei, Taiwan. ${ }^{4}$ Department of Internal Medicine, School of Medicine, College of Medicine, Taipei Medical University, Taipei, Taiwan. ${ }^{5}$ Graduate Institute of Medical Sciences, School of Medicine, College of Medicine, Taipei Medical University, Taipei, Taiwan. ${ }^{6}$ Division of Gastroenterology, Cheng Hsin General Hospital, Taipei, Taiwan. ${ }^{7}$ Nursing Department, Kang-Ning University, Taipei, Taiwan.
\end{abstract}

Received: 3 September 2015 Accepted: 11 January 2016

Published online: 28 January 2016

\section{References}

1. Richard DE, Berra E, Pouyssegur J. Angiogenesis: how a tumor adapts to hypoxia. Biochem Biophys Res Commun. 1999;266(3):718-22. doi:10.1006/bbrc.1999.1889

2. Lungu GF, Li ML, Xie X, Wang LV, Stoica G. In vivo imaging and characterization of hypoxia-induced neovascularization and tumor invasion. Int J Oncol. 2007; 30(1):45-54.

3. Tsai JR, Wang HM, Liu PL, Chen YH, Yang MC, Chou SH, et al. High expression of heme oxygenase-1 is associated with tumor invasiveness and poor clinical outcome in non-small cell lung cancer patients. Cell Oncol. 2012;35(6):461-71. doi:10.1007/s13402-012-0105-5.

4. Lartigau E. Tissue hypoxia, tumor angiogenesis and radiotherapy. Therapie. 2001;56(5):495-9.

5. Carlson DJ, Yenice KM, Orton CG. Tumor hypoxia is an important mechanism of radioresistance in hypofractionated radiotherapy and must be considered in the treatment planning process. Med Phys. 2011;38(12):6347-50. doi:10.1118/1.3639137.
6. Maxwell PH, Dachs GU, Gleadle JM, Nicholls LG, Harris AL, Stratford IJ, et al. Hypoxia-inducible factor-1 modulates gene expression in solid tumors and influences both angiogenesis and tumor growth. Proc Natl Acad Sci U S A. 1997:94(15):8104-9.

7. Ryan HE, Poloni M, McNulty W, Elson D, Gassmann M, Arbeit JM, et al. Hypoxia-inducible factor-1alpha is a positive factor in solid tumor growth. Cancer Res. 2000;60(15):4010-5.

8. Liu YS, Li HS, Qi DF, Zhang J, Jiang XC, Shi K, et al. Zinc protoporphyrin IX enhances chemotherapeutic response of hepatoma cells to cisplatin. World J Gastroenterol. 2014;20(26):8572-82. doi:10.3748/wjg.v20.i26.8572.

9. Hjortso MD, Andersen $\mathrm{MH}$. The expression, function and targeting of haem oxygenase-1 in cancer. Curr Cancer Drug Targets. 2014;14(4):337-47.

10. Lee PJ, Jiang BH, Chin BY, lyer NV, Alam J, Semenza GL, et al. Hypoxia-inducible factor-1 mediates transcriptional activation of the heme oxygenase-1 gene in response to hypoxia. J Biol Chem. 1997;272(9):5375-81.

11. Zhang M, Hou M, Ge L, Miao C, Zhang J, Jing X, et al. Induction of peroxiredoxin 1 by hypoxia regulates heme oxygenase-1 via NF-kappaB in oral cancer. PloS One. 2014;9(8), e105994. doi:10.1371/journal.pone.0105994.

12. Chau LY. Heme oxygenase-1: emerging target of cancer therapy. J Biomed Sci. 2015;22:22. doi:10.1186/s12929-015-0128-0.

13. Abraham NG, Kappas A. Pharmacological and clinical aspects of heme oxygenase. Pharmacol Rev. 2008;60(1):79-127. doi:10.1124/pr.107.07104.

14. Fan J, Xu G, Jiang T, Qin Y. Pharmacologic induction of heme oxygenase-1 plays a protective role in diabetic retinopathy in rats. Investig Ophthalmol Vis Sci. 2012;53(10):6541-56. doi:10.1167/iovs.11-9241.

15. Huang HF, Zeng Z, Wang KH, Zhang HY, Wang S, Zhou WX, et al. Heme oxygenase-1 protects rat liver against warm ischemia/reperfusion injury via TLR2/TLR4-triggered signaling pathways. World J Gastroenterol. 2015;21(10): 2937-48. doi:10.3748/wjg.v21.i10.2937.

16. Li XH, Gong X, Zhang L, Jiang R, Li HZ, Wu MJ, et al. Protective effects of polydatin on septic lung injury in mice via upregulation of $\mathrm{HO}-1$. Mediat Inflamm. 2013;2013:354087. doi:10.1155/2013/354087.

17. Miao RZ, Liu LQ, Chen L, Li Z, Li LP, Guo RL, et al. Activity of heme oxygenase-1 affects expression levels of hypoxia inducible factor-1 gene in vitro. Chin Med J. 2012;125(7):1310-5

18. Nuhn P, Kunzli BM, Hennig R, Mitkus T, Ramanauskas T, Nobiling R, et al. Heme oxygenase-1 and its metabolites affect pancreatic tumor growth in vivo. Mol Cancer. 2009:8:37. doi:10.1186/1476-4598-8-37.

19. Alaoui-Jamali MA, Bismar TA, Gupta A, Szarek WA, Su J, Song W, et al. A novel experimental heme oxygenase-1-targeted therapy for hormonerefractory prostate cancer. Cancer Res. 2009;69(20):8017-24. doi:10.1158/ 0008-5472.CAN-09-0419.

20. Yin H, Fang J, Liao L, Maeda H, Su Q. Upregulation of heme oxygenase-1 in colorectal cancer patients with increased circulation carbon monoxide levels, potentially affects chemotherapeutic sensitivity. BMC Cancer. 2014;14: 436. doi:10.1186/1471-2407-14-436.

21. Was H, Dulak J, Jozkowicz A. Heme oxygenase-1 in tumor biology and therapy. Curr Drug Targets. 2010;11(12):1551-70.

22. Sass G, Leukel P, Schmitz V, Raskopf E, Ocker M, Neureiter D, et al. Inhibition of heme oxygenase 1 expression by small interfering RNA decreases orthotopic tumor growth in livers of mice. Int J Cancer. 2008;123(6):1269-77. doi:10.1002/ijc.23695

23. Wang S, Avery JE, Hannafon BN, Lind SE, Ding WQ. Zinc protoporphyrin suppresses cancer cell viability through a heme oxygenase-1-independent mechanism: the involvement of the Wnt/beta-catenin signaling pathway. Biochem Pharmacol. 2013;85(11):1611-8. doi:10.1016/j.bcp.2013.03.011.

24. Kappas A, Drummond GS. Control of heme metabolism with synthetic metalloporphyrins. J Clin Investig. 1986;77(2):335-9. doi:10.1172/JCl112309.

25. Kyzas PA, Stefanou D, Batistatou A, Agnantis NJ. Hypoxia-induced tumor angiogenic pathway in head and neck cancer: an in vivo study. Cancer Lett. 2005;225(2):297-304. doi:10.1016/j.canlet.2004.11.060.

26. Jensen RL, Ragel BT, Whang K, Gillespie D. Inhibition of hypoxia inducible factor-1alpha (HIF-1alpha) decreases vascular endothelial growth factor (VEGF) secretion and tumor growth in malignant gliomas. J Neuro-Oncol. 2006;78(3):233-47. doi:10.1007/s11060-005-9103-z.

27. Morfoisse F, Kuchnio A, Frainay C, Gomez-Brouchet A, Delisle MB, Marzi S, et al. Hypoxia induces VEGF-C expression in metastatic tumor cells via a HIF-1alphaindependent translation-mediated mechanism. Cell Rep. 2014;6(1):155-67. doi: 10.1016/j.celrep.2013.12.011.

28. Miyata Y, Kanda S, Mitsunari K, Asai A, Sakai H. Heme oxygenase-1 expression is associated with tumor aggressiveness and outcomes in patients with bladder 
cancer: a correlation with smoking intensity. Transl Res. 2014;164(6):468-76. doi:10.1016/j.trsl.2014.06.010

29. Chen WT, Huang CJ, Wu MT, Yang SF, Su YC, Chai CY. Hypoxia-inducible factor-1alpha is associated with risk of aggressive behavior and tumor angiogenesis in gastrointestinal stromal tumor. Jpn J Clin Oncol. 2005;35(4): 207-13. doi:10.1093/jico/hyi067.

30. Raiter A, Yerushalmi R, Hardy B. Pharmacological induction of cell surface GRP78 contributes to apoptosis in triple negative breast cancer cells. Oncotarget. 2014;5(22):11452-63.

31. Le Tourneau C, Faivre S, Raymond E. The role of integrins in colorectal cancer. Oncology. 2007;21 (9 Suppl 3):21-4.

32. Ellis LM. A targeted approach for antiangiogenic therapy of metastatic human colon cancer. Am Surg. 2003;69(1):3-10.

33. Rattan $\mathrm{S}$, Chakder $\mathrm{S}$. Influence of heme oxygenase inhibitors on the basal tissue enzymatic activity and smooth muscle relaxation of internal anal sphincter. J Pharmacol Exp Ther. 2000;294(3):1009-16.

34. Tanaka S, Akaike T, Fang J, Beppu T, Ogawa M, Tamura F, et al. Antiapoptotic effect of haem oxygenase-1 induced by nitric oxide in experimental solid tumour. Br J Cancer. 2003;88(6):902-9. doi:10.1038/sj.bjc.6600830.

35. La P, Fernando AP, Wang Z, Salahudeen A, Yang G, Lin Q, et al. Zinc protoporphyrin regulates cyclin D1 expression independent of heme oxygenase inhibition. J Biol Chem. 2009;284(52):36302-11. doi:10.1074/jbc. M109.031641.

36. Fang J, Sawa T, Akaike T, Akuta T, Sahoo SK, Khaled G, et al. In vivo antitumor activity of pegylated zinc protoporphyrin: targeted inhibition of heme oxygenase in solid tumor. Cancer Res. 2003;63(13):3567-74

37. Eggert A, Ikegaki N, Kwiatkowski J, Zhao H, Brodeur GM, Himelstein BP. High-level expression of angiogenic factors is associated with advanced tumor stage in human neuroblastomas. Clin Cancer Res. 2000;6(5):1900-8.

38. Montet X, Figueiredo JL, Alencar H, Ntziachristos V, Mahmood U, Weissleder R. Tomographic fluorescence imaging of tumor vascular volume in mice. Radiology. 2007;242(3):751-8. doi:10.1148/radiol.2423052065.

39. Haller J, Hyde D, Deliolanis N, de Kleine R, Niedre M, Ntziachristos V. Visualization of pulmonary inflammation using noninvasive fluorescence molecular imaging. J Appl Physiol. 2008;104(3):795-802. doi:10.1152 japplphysiol.00959.2007.

40. Lee JM, Lee WH, Kay HY, Kim ES, Moon A, Kim SG. Hemin, an iron-binding porphyrin, inhibits HIF-1alpha induction through its binding with heat shock protein 90. Int J Cancer. 2012;130(3):716-27. doi:10.1002/ijc.26075.

41. Chun YS, Choi E, Kim GT, Lee MJ, Lee MJ, Lee SE, et al. Zinc induces the accumulation of hypoxia-inducible factor (HIF)-1alpha, but inhibits the nuclear translocation of HIF-1 beta, causing HIF-1 inactivation. Biochem Biophys Res Commun. 2000;268(2):652-6. doi:10.1006/bbrc.2000.2180.

42. Nardinocchi L, Pantisano V, Puca R, Porru M, Aiello A, Grasselli A, et al. Zinc downregulates HIF-1alpha and inhibits its activity in tumor cells in vitro and in vivo. PloS one. 2010;5(12), e15048. doi:10.1371/journal.pone.0015048.

\section{Submit your next manuscript to BioMed Central and we will help you at every step:}

- We accept pre-submission inquiries

- Our selector tool helps you to find the most relevant journal

- We provide round the clock customer support

- Convenient online submission

- Thorough peer review

- Inclusion in PubMed and all major indexing services

- Maximum visibility for your research

Submit your manuscript at www.biomedcentral.com/submit
Biomed Central 